\title{
A systematic review reveals changes in where and how we have stud- ied habitat loss and fragmentation over 20 years
}

\section{Submitted version}

Authors: Dini Fardila ${ }^{1}$, Luke T. Kelly ${ }^{1}$, Joslin L. Moore ${ }^{1,2}$, Michael A. McCarthy ${ }^{1}$

\author{
Affiliations: \\ ${ }^{1}$ School of BioSciences, ARC Centre of Excellence for Environmental Decisions, \\ University of Melbourne, Parkville, Victoria 3010, Australia. \\ ${ }^{2}$ School of Biological Sciences, Monash University, Caulfield, Victoria 3800, \\ Australia.
}

Corresponding author: Luke T. Kelly

Address: School of BioSciences, ARC Centre of Excellence for Environmental Decisions, University of Melbourne, Parkville, Victoria 3010, Australia.

Email: ltkelly@unimelb.edu.au

The final version is available from the corresponding author (ltkelly@unimelb.edu.au) or via https://www.journals.elsevier.com/biological-conservation and should be cited as:

Fardila, D., Kelly, L.T., Moore, J.L., \& McCarthy, M.A. (2017) A systematic review reveals changes in where and how we have studied habitat loss and fragmentation over 20 years. Biological Conservation, 212, Part A, 130-138. 


\section{Title:}

2 A systematic review reveals changes in where and how we have studied habitat loss

3 and fragmentation over 20 years

4

5 Authors: Dini Fardila ${ }^{1}$, Luke T. Kelly ${ }^{1}$, Joslin L. Moore ${ }^{1,2}$, Michael A. McCarthy ${ }^{1}$

$6{ }^{1}$ School of BioSciences, ARC Centre of Excellence for Environmental Decisions,

7 University of Melbourne, Parkville, Victoria 3010, Australia.

$8{ }^{2}$ School of Biological Sciences, Monash University, Caulfield, Victoria 3800,

9 Australia.

11 Corresponding author: Luke T. Kelly

12 Address: School of BioSciences, ARC Centre of Excellence for Environmental

13 Decisions, University of Melbourne, Parkville, Victoria 3010, Australia.

14 Email: ltkelly@unimelb.edu.au

15

16 


\section{Abstract}

Habitat loss and fragmentation are global threats to biodiversity and major research topics in ecology and conservation biology. We conducted a systematic review to assess where - the geographic locations and habitat types - and how - the study designs, conceptual underpinnings, landscape metrics and biodiversity measures scientists have studied fragmentation over the last two decades. We sampled papers from 1994 to 2016 and used regression modelling to explore changes in fragmentation research over time. Habitat loss and fragmentation studies are geographically and taxonomically biased. Almost 85\% of studies were conducted in America and Europe, with temperate forests and birds the most studied groups. Most studies use a binary conceptual model of landscapes (habitat versus non-habitat) and static measures of biodiversity. However, research on fragmentation is slowly shifting from a focus on coarse patterns to more nuanced representations of biodiversity and landscapes that better represent ecological processes. For example, empirical research based on gradient or continuum models, that offer new insights into landscape complexity and species-specific responses to habitat fragmentation, are increasing in prevalence. We recommend that fragmentation research focuses on developing knowledge on underlying mechanisms and processes of how species respond to landscape changes, and that fragmentation studies be conducted in the full range of habitats currently experiencing high rates of landscape modification. This is crucial if we are to understand relationships between biodiversity and ecosystems and to develop effective management strategies in fragmented landscapes.

Key words: biodiversity, connectivity, continuum model, global change, landscape mosaic, taxonomic bias 5 6 67 8 0 1 2 (3) 5 6 7 


\section{Introduction}

Over the last century, habitat loss and fragmentation have been the main drivers of biodiversity change in terrestrial ecosystems (Laurance et al. 2012; Newbold et al. 2015). A recent synthesis of 35 years of fragmentation experiments across multiple spatial scales revealed that habitat loss and fragmentation has reduced biodiversity by 13 to $75 \%$ in five continents, and more than $70 \%$ of the world's remaining forests are now in close proximity to modified environments (Haddad et al. 2015). Rapid habitat loss and fragmentation is particularly concerning in biodiversity hotspots such as tropical forests and temperate grasslands, and these trends are likely to continue (Millennium Ecosystem Assessment 2005; Gardner et al. 2009).

Given its important role in global change, habitat loss and fragmentation continues to be an important research topic in ecology and conservation biology (Tscharntke et al. 2012; Driscoll et al. 2013). The literature on fragmented landscapes is vast and growing: a search of "habitat fragmentation" in Thomson Reuters Web of Science (environmental science ecology research area) from 1980 yielded over 3,800 published papers, or more than $10 \%$ of total ecology papers available. Rapid progress has been in made in habitat loss and fragmentation research in only a few decades, and the results of this work have particularly influenced applied problems such as design of nature reserves, and management of agricultural landscapes, urban areas and forest harvesting (Lindenmayer et al. 2006). However, identifying and quantifying general patterns and processes in this large body of literature remains difficult. The fragmentation literature encompasses many experimental designs and methods (Bennett et al. 2006), choices of landscape measurements (Kool et al. 2013), landscape classifications (Lindenmayer and Fischer 2007), and ways of representing biodiversity (Ewers and Didham 2006).

To synthesise habitat loss and fragmentation research, much effort has been applied to the development of the theoretical concepts and landscape models that underpin our understanding of these processes (Fischer and Lindenmayer 2007; Price et al. 2009; Laurance et al. 2011b; Didham et al. 2012). A simple and influential conceptual model of habitat fragmentation is based on island biogeography theory (MacArthur and Wilson 1967). This binary view of habitat and non-habitat (e.g. Diamond 1975) led to the development of more complex ways of classifying landscapes such as the patch-corridor-matrix model (Forman and Godron 1981), the landscape mosaic model (Wiens 1995), and, more recently, models that recognise habitat gradients and continuums (McIntyre and Hobbs 1999; Manning et al. 2004; McGarigal and Cushman 2005; Fischer and Lindenmayer 2006). A shift from a simple binary model to more complex mosaic and continuum models requires new ways of measuring landscape patterns. We predict that methods to measure landscapes have kept up with the development of these conceptual models. However, which methods have developed and how fast they have developed remains unclear.

Numerous metrics have been developed to measure landscape composition (identity and characteristics of landscape elements), configuration (spatial arrangement of landscape elements), and connectivity (the ease with which organisms move through the landscape) (Hanski 1994; Hargis et al. 1998; Tischendorf and Fahrig 2000). A range of tools and software have also been developed to assist this quantification (e.g. "FRAGSTATS" (McGarigal et al. 2002), "Circuitscape" (Shah and McRae 2008), and "Conefor" (Saura and Torne 2009). Landscape metrics have been used to describe habitat loss and fragmentation at a range of different spatial scales 
from patches to whole landscapes (Bennett et al. 2006). Despite development in experimental design and landscape measures, the use of different approaches has led to very different conclusions regarding the magnitude and direction of fragmentation effects (Fahrig 2003). There is little consensus regarding which aspects of landscape structure and composition should be studied for describing biodiversity responses to fragmentation (Ewers et al. 2010; Fahrig 2015; Hanski 2015). Several narrative reviews have highlighted the range of landscape metrics available (Kool et al. 2013), and alternative ways to study landscape change (Brennan et al. 2002; Bennett et al. 2006; Fahrig et al. 2011), but few studies have quantified how the use of metrics and alternative study designs is changing over time.

Another issue relates to taxonomic and geographical biases in ecology. Ideally, fragmentation research should comprehensively cover a range of geographical regions and taxonomic groups to provide robust data that support effective conservation policies and actions. We predict that, as in conservation biology and ecology more broadly (Trimble and van Aarde 2012; Burgman et al. 2015), our knowledge of how habitat fragmentation and landscape patterns affect biota is biased towards large faunas in temperate regions. These forms of bias will be particularly problematic if fragmentation affects geographic regions and taxa in different ways (Thornton et al. 2011).

Systematic review is an important tool for evaluating conservation evidence and supporting environmental decision making (Pullin and Knight 2009). It is also useful for identifying knowledge gaps and methodological inconsistencies across disciplines and to focus research priorities (Pullin and Knight 2009; Mallett et al. 2012; Haddaway and Pullin 2014). To date, researchers have systematically reviewed habitat loss and fragmentation studies for specific sections of the literature including experimental manipulations of habitat fragmentation (Debinski and Holt 2000; McGarigal and Cushman 2002), the interactions between climate and habitat loss (Mantyka-Pringle et al. 2012), the use of landscape spatial metrics (Uuemaa et al. 2013), dispersal research for landscape planning and restoration (Driscoll et al. 2014), and within particular habitat types (e.g. tropical forests, Deikumah et al. 2014). However, systematic analyses of the broader literature on habitat loss and fragmentation, including a range of ecosystems, study types and measures, are rare and few have examined how the literature has changed over time.

In this paper, we systematically review the development of habitat loss and fragmentation research over more than 20 years to identify where and how research has been undertaken and in what way it has changed over time. Specifically, we asked: 1) What conceptual models have been used in fragmentation studies, and how have the use of these models changed over time? 2) How have biodiversity responses to landscape modification been measured, and how have these measures changed over time? 3) What landscape metrics have been used to describe habitat loss and fragmentation, and how have their use changed over time? and 4) How are these studies distributed across regions, habitat types and taxa?

\section{Methods}

To examine trends in habitat loss and fragmentation studies, we undertook a systematic review of the literature. For each paper in our sample we recorded information on the study design, geographic region and taxa considered, and the 
underlying conceptual model, the biodiversity responses measured, and the landscape metrics used. We then modelled how these attributes have changed over time using logistic regression.

\section{Systematic literature search}

We first conducted a search of all peer-reviewed ecological articles indexed by the Thomson Reuters Web of Science Core Collection (Sci-Expanded) from 1 January 1980 to 31 June 2016 using the keyword "ecology". We initially searched papers starting from the 1980's because this was when landscape ecology clearly emerged as a unique scientific discipline (Wiens 2007). We refined the search by type of document (article), research area (environmental science-ecology), and language (English), which resulted in 39,045 articles. We conducted another search using keywords that are related to habitat fragmentation and landscape change: "habitat fragmentation" or "forest fragmentation" or "grassland fragmentation" or "woodland fragmentation" or "savanna fragmentation" or "shrubland fragmentation" or "tundra fragmentation" or "heathland fragmentation" or "xeric shrubland fragmentation" or "scrub fragmentation" or "desert fragmentation" or "mangrove fragmentation" or "river fragmentation" or "landscape fragmentation" or "habitat connectivity" or "landscape connectivity" or "patch connectivity" or "patch isolation" or "habitat isolation". This search resulted in a subset of 6,341 articles from the broader sample. Using both searches, we then calculated the proportion of fragmentation studies within ecological science for each year to examine the prevalence of fragmentation studies in the ecological literature (supplementary material S1, Fig. A1).

A check of additional search terms including "fragment*", "isolat*" and "connect*" in Web of Science increased the total number of papers found by approximately $10 \%$. Because adding these new terms added only a relatively small number of additional papers we present the results from our original search in the present paper.

As the number of fragmentation papers increased substantially in the beginning of the 1990's, we decided to limit our systematic review to 6,252 papers that were published between 1994 and 2016 (23 years). This guaranteed that we sampled enough papers in each year to develop statistical models of changes in the literature. We randomly selected 20 articles from each of the 23 years (460 in total). We screened the selected articles and excluded articles that did not measure habitat loss and fragmentation or did not examine fragmentation effects on biodiversity. We also excluded articles that did not present empirical or simulated data (including review papers and opinion papers). The remaining 302 focal articles were then reviewed in full for data extraction (Fig. 1). Finally, we calculated the standard error of the sample population for each year to ensure we had a large enough sample size to complete our analysis (following Sokal and Rohlf (1995)). The number of papers analysed each year is presented in Table A2.

\section{Classification of the literature}

We categorised each of the focal articles by a range of attributes including study design (type of study, source of data, unit of inference), conceptual model of habitat loss and fragmentation, type of landscape metric, type of biotic response, geographic location, biome, focal organism, species conservation status, and highest 
level of biological organisation (Table A3). For attributes of study design, conceptual model, and highest organisational level, each study was allocated to a single category. For other attributes, studies could be allocated to multiple categories. We examined the reliability of classification by having two of the authors (DF and LTK) read the same subsample of papers and checking that the categorisation of papers matched.

\section{Research Topic}

We examined trends in the number of published papers with respect to each study attribute. To analyse the trends, we first calculated the proportion of studies in each category of attribute for each calendar year. We then conducted a logistic regression to calculate the rate of change in the proportion of studies per year for each category:

where $y(i)$ is the proportion of studies in year $i, \beta_{0}$ is the model intercept, $\beta_{1}$ is the rate of change, and $x_{i}$ is year $i$. We first specified a binomial distribution for each model, and, where the dispersion of the residuals suggested over- or under-dispersion, we used quasibinomial regression and beta regression, respectively (Hilbe 2009).

We also calculated the predicted number of all fragmentation papers in each category based on the logistic model and the difference in predicted number of papers between years 2016 and 1994 to estimate changes in number of papers in 23 years. To do this, we first computed the predicted number of papers for each category from the fitted values of logistic regression:

$$
\hat{p}(i)=\frac{\left.e^{(\beta 0+\beta 1 \times i}\right)}{\left.1+e^{(\beta 0+\beta 11 x i}\right)} \times \text { number of fragmentation papers in year } i
$$

We then calculated the changes in 23 years as:

$\Delta \hat{\mathrm{p}}=\hat{\mathrm{p}}(2016)-\hat{\mathrm{p}}(1994)$

These changes represented the predicted number of fragmentation papers published between 1994 and 2016, with respect to each topic. We used package 'MASS' (Venables and Ripley 2002) in R version 3.2.2 for all logistic regression analyses (additional details in supplementary material S4, Table A4). We also analysed potential interactions in the use of conceptual models across different habitat types and regions using chi-square tests in the R Base Package.

\section{Results}


The keyword search for the systematic review returned a total of 6,252 articles published between 1994 and 2016. The 460 sampled articles came from 87 different scientific journals. Biological Conservation and Conservation Biology were the most prevalent journals (9.8\% and 7.8\%, respectively). Landscape Ecology, Biodiversity and Conservation and Ecological Applications rounded out the top five journals (6.7\%, 5.2\% and 4.8\% of articles, respectively). A full list of journals is presented in Table A5.

\section{Study design}

Of the 302 focal articles reviewed, the majority reported new data (90.4\%), while the rest used existing data sets (6.0\%) or simulated data (3.6\%). Most of the articles used natural experiments (76.5\%) and field experiments (15.9\%). Few studies were solely based on simulations $(6.6 \%)$ or laboratory experiments $(1 \%)$.

Almost half of the studies measured fragmentation using a focal patch approach (47\%), that takes into account the effects of the surrounding landscape on species responses to habitat loss and fragmentation. A similar number of studies used individual patches as the unit of inference (45.7\%). Only $7.3 \%$ of the studies used a "whole-of-landscape" approach where both the response and predictor variables were measured at a landscape-level. Despite their lower prevalence, landscape-level studies have increased as a proportion over the past 23 years, whereas patch-level studies have decreased (Fig. 2).

\section{Conceptual model}

Studies more commonly conformed to a binary conceptual model (73.5\%) than a mosaic (15.9\%) or continuum model (10.6\%). However, over time the use of the binary model decreased as a proportion of total fragmentation studies (Fig. 3). By contrast, the continuum and mosaic models are being increasingly used (Fig. 3). There was no difference in the use of conceptual model among habitat types $\left(\chi^{2}(7, \mathrm{~N}=293)=\right.$ 8.06, $\mathrm{p}>0.05)$ or regions $\left(\chi_{(5, \mathrm{~N}=293)}^{2}=8.66, \mathrm{p}>0.05\right)($ Tables A6 and A7).

\section{Species response}

More than half (61.3\%) of the studies measured the effect of habitat fragmentation on species distributions (i.e. biodiversity measured as abundance, occurrence or changes in range size) (Fig. 4). Measures of diversity and population dynamics were also commonly used (34.4\% and $28.1 \%$, respectively). Other response variables, such as movement (13.2\%), genetics (12.9\%), morphology/physiology (11.9\%) and biotic interactions (11.3\%) were less common measurements. Despite their lower percentages, studies examining movement and morphology/physiology are becoming more common (Fig. 4). Although there was a decrease in the proportion of papers that focused on species distributions, the total number of studies that examined this response increased more than any other measures over 23 years.

\section{Landscape metric}


Area metrics and isolation/proximity metrics were those most commonly used in our sample of the fragmentation literature ( $48 \%$ and $42.4 \%$, respectively). The use of area metrics has significantly decreased over time, whereas isolation/proximity metrics have increased moderately (Fig. 5). Measures including core area, disturbance/succession, contrast, and patch type decreased in prevalence, while least cost models, graph theory, and incidence function model have started to be used more frequently. Despite declining proportional rates of use, the absolute number of studies that used measures of patch area and habitat amount was still growing (Fig. 5).

\section{Geographic location and habitat type}

We identified several locational biases (Fig. 1). Most articles examined fragmentation in regions with extensive temperate vegetation such as Northern America (36.8\%), Australia/New Zealand (12.9\%), Western Europe (12.3\%) and Northern Europe (7.6\%) (Fig. 6). A smaller percentage of studies were conducted in regions containing large areas of tropical vegetation such as South America (13.2\%) and Central America (7.9\%). Africa, most parts of Asia, and southern and eastern parts of Europe were the least represented regions in our sample, and none of the random subset of 302 papers reviewed described studies conducted in the Caribbean, Central Asia, Polynesia, Micronesia or Northern Africa. Nevertheless, over the past 23 years, the absolute number of studies conducted in Asia, Africa and South America was increasing (Fig. 6).

Fragmentation studies were also biased by habitat, with most studies conducted in temperate ecosystems. More studies were conducted in temperate forests (43\%) than tropical and subtropical forests (21.5\%), despite the greater extent of tropical and subtropical forests. The number of papers about tropical and subtropical forests increased substantially over time, as did the number of papers focusing on freshwater ecosystems (Fig. A8). In both temperate and tropical areas, grassland ecosystems received less attention compared to forests, however grassland-focused studies in tropical systems increased over time. Tropical grasslands/savannas, deserts/xeric shrublands, and boreal forests all cover relatively large areas (Fig. A9), but were among the least represented habitats (4.3\%, $4 \%$ and $3.6 \%$ of studies, respectively) (Fig. A8).

\section{Taxonomic group, status and organisational level}

Few taxonomic groups were well represented (Fig. 7). Birds and mammals were most commonly studied (27.5\% and $22.8 \%$ of studies, respectively). Other vertebrate taxa such as amphibians, reptiles and fishes were represented infrequently (5.6\%, $4.6 \%$, and $2.3 \%$ of studies, respectively). Vascular plants were represented in nearly a quarter of sampled studies (24.2\%). Of the 62 papers studying invertebrates, most studied insects (49 papers, $16.2 \%$ of focal studies). Only molluscs were represented in the studies of non-arthropod invertebrate taxa (1.7\%).

Of the 155 papers where species status could be identified, studies on nonthreatened species (57.4\%) were far more common than those of threatened (16.1\%). Most studies were conducted at assemblage level (43.4\%), or single (individual) species level (40.1\%), whereas few studies analysed the effects of fragmentation at community and ecosystem levels (13.2\% and $2.3 \%$, respectively). There was an 
increasing trend in single species studies, while studies of multiple species decreased or were static (Fig. 7).

\section{Discussion}

Habitat loss and fragmentation have been a major research focus for ecologists and conservation biologists over the past 23 years, constituting as much as $20 \%$ of all studies in ecology and environmental research in some years. We present evidence for preferential selection of conceptual models used to define fragmentation, the biodiversity responses examined, and the landscape metrics used for measuring fragmentation. Overall, our systematic review shows that research on habitat loss and fragmentation is shifting from a focus on coarse patterns to more nuanced representations of biodiversity and landscapes that better represent ecological processes, although at slower rate than we expected. These new insights into how fragmentation research is changing over time were only possible through systematic review spanning more than two decades.

Simple conceptual models remained popular, but the use of more complex models increased

As predicted, there was a strong preference for using a binary model of landscape classification in fragmentation research. The binary model was among the first conceptual models developed to describe patterns of landscape change (Haila 2002), and it is relatively easy to implement because of its simple representation of landscapes and minimal data requirements. The binary model is well suited for landscapes that are dominated by clearly defined boundaries, units or patches. However, many landscapes consist of continuous gradients or mosaics of different elements, and the binary model can oversimplify habitat fragmentation (Fischer and Lindenmayer 2006). For example, a pixel-by-pixel comparison of a binary and a continuous map showed that around $87 \%$ of the habitat quality information in the continuous map could not be accounted for by the binary map (Cushman et al. 2010).

In one of few studies to empirically test the use of different landscape conceptual models, Price et al. (2009) showed that the usefulness of different models varied among species, depending on species associations with different landscape elements. Despite the large number of studies using binary models, studies that represent landscapes as continuums are increasing at a greater rate. Technological advances in remote sensing and data analysis, as well as advances in our understanding of landscape connectivity, have assisted the shift towards more complex landscape models by enabling researchers to collect and analyse more complex data on habitat fragmentation (Duputie et al. 2014).

In summary, discrete models can provide useful representations of landscapes with clear spatial boundaries that have been demonstrably linked to species distributions (Dunn and Majer 2007). Gradient models, by contrast, can provide insight on species responses in landscapes with less marked transitional boundaries (Bruton et al. 2015). There is a trade-off between information content and data requirements across different fragmentation models. The choice of conceptual model should be determined by the research question asked, the ecosystem studied, the scale of observation, and the availability of data and tools needed for the analysis. 
395 The majority of studies measured fragmentation at the patch or focal patch 396 level. Although only 7\% of the studies used a "whole-of-landscape" approach - where 397 both the response and predictor variables were measured at a landscape-level (Bennett

398

399

400

401

402

403

404

405

406

407

408

409

410

411

412

413

414

415

416

417

418

419

420

421

422

423

424

425

426

427

428

429

430

431

432

433

434

435

436

437

438 et al. 2006) - this landscape study design has become more common over the past 23 years. A whole-of-landscape approach has provided new insights into the relative influence of landscape composition and configuration on biodiversity in fragmented landscapes (Fahrig et al. 2011) - with most empirical studies to-date showing stronger effects of landscape composition, rather than configuration, on biodiversity (Radford and Bennett 2007; Haslem and Bennett 2008; Mortelliti et al. 2011).

\section{Pattern-based measures of biotic responses were preferred}

Preferences in the underlying fragmentation model were reflected in the choice of biological responses and landscape metrics used in the studies. Overall, static counts of biodiversity such as abundance and species richness were the most common response variables. These measurements are commonly used because they are easy to calculate and interpret, and because they often explain and predict species responses to habitat fragmentation (Colwell 2009). However, as these measures emphasise pattern, they may provide an inadequate representation of some biological processes (Turner 2006). On the other hand, process-based measures such as population dynamics, biotic interactions and dispersal are typically more difficult to measure, requiring extensive measurements and pose more methodological challenges. This may explain the reduced attention given to these measures in fragmentation studies. The complexity of these measures, however, comes with the advantage of more realistic prediction of the interactions between species distribution and characteristics of particular landscapes (Wiegand et al. 2005).

Studies of animal movement are increasing in prevalence, but process-based measurements relating to population dynamics are decreasing in prevalence. The growing interest in movement studies that we identified is likely due to recent advances in technology used for observing species dispersal, such as radio, satellite and radar tracking (Nathan et al. 2003; Bridge et al. 2011), as well as the rapid development of methods for species distribution modelling (Bocedi et al. 2014). Studies that incorporate population dynamics require substantial field data to calculate and parameterise demographic models (Baguette 2004).

\section{Pattern-based landscape metrics are common, but there is an increasing trend for process-based metrics}

The use of relatively simple landscape measurements such as area and distance for quantifying landscape pattern remain popular in fragmentation research and can be suitable for making conservation decisions (Calabrese and Fagan 2004). However, we identified an increasing trend in the use of metrics that aim to capture a greater range of the landscape elements that determine species responses to habitat loss and fragmentation. These metrics, including incidence function models, least cost models and graph theory, can incorporate ecological processes such as movement and population dynamics in their calculation (Prugh 2009). By combining physical 
attributes of the landscape with the species information, these metrics offer the potential to quantify how habitat loss and fragmentation influence animal movement, connectivity and landscape resistance (Shah and McRae 2008). The advantages of using metrics that incorporate multiple landscape elements and ecological processes, however, come at a cost of greater complexity, as they can be difficult to use and require labour-intensive data collection. We hypothesise that this explains the lower proportion of process-based metrics in our systematic review.

\section{Fragmentation studies were geographically and taxonomically biased}

The majority of fragmentation research has been carried out in relatively wealthy countries. However, most natural ecosystems and biodiversity hotspots are located in developing parts of Asia, Africa and South America that are currently experiencing the most rapid change (Myers et al. 2000; Smith et al. 2003; Fearnside 2005; Newbold et al. 2015; Fig. A9). The relatively small number of fragmentation studies conducted in these regions is likely due to limited financial support, inadequate infrastructure and political instability (Holmgren and Schnitzer 2004). Lack of quantitative ecological training in developing countries, and language barriers, have also potentially impeded the amount and quality of research in particular geographic locations (Griffiths and Dos Santos 2012). A recent review revealed that only $7 \%$ of ecology and biodiversity conservation submissions, in one international journal, came from Africa, Asia, Central and South America, whereas submission from North America, Oceania and Europe were three times as common (Burgman et al. 2015).

Geographic and taxonomic biases are acknowledged in ecology and conservation biology. Nevertheless, Cronin et al. (2014), in a review of the broader wildlife conservation literature, reported that there has been some increase in research undertaken in tropical regions such as Central America, South America, Southern Asia, and South-eastern Asia over the past 20 years. This is consistent with our observations for the fragmentation literature. Notable habitat loss and fragmentation studies include the Borneo Futures Project in Indonesian and Malaysian Borneo (Wilson et al. 2010), the Biological Dynamics of Forest Fragments Project in Brazil (Laurance et al. 2011a), and the Stability of Altered Forest Ecosystem (SAFE) Project in Malaysian Borneo (Ewers et al. 2011).

We only reviewed papers written in English and this might have biased the geographic distribution of the studies we sampled. There is a need to better integrate studies published in languages other than English with the broader international literature. To facilitate better integration of research from under-represented countries, useful actions include enhancing training of local conservation biologists, communitybased organisations and field staff through higher-level education, and promoting partnerships and research visits among local researchers and international research institutions.

Compared to forests, grasslands and aquatic habitats have received much less attention in fragmentation studies. This could reflect the focus of early landscape ecology studies on forest ecosystems. For example, a search of the phrase "grassland fragmentation" resulted in less than $2 \%$ of the hits returned for "forest fragmentation". In a recent review, Wilson et al. (2012) found that grasslands harbour more plant species at smaller spatial grains (less than $50 \mathrm{~m}^{2}$ quadrats) compared to tropical 
rainforests. Moreover, grasslands are generally considered to be more vulnerable than forests to habitat destruction because they are easy to cultivate and their location often makes them vulnerable to overgrazing and urbanisation (Dauber et al. 2006; Newbold et al. 2016). We recommend fragmentation studies be conducted in the full range of habitats currently experiencing high rates of landscape modification because threats to biodiversity are not restricted to forests.

Fragmentation research has been dominated by work on birds, mammals and vascular plants, presumably because larger animals and plants are valued by people, are a priority for most conservation managers and are relatively cost-effective to study. However, there is a risk that such biases could limit understanding of relationships between understudied taxa and their environments, and thus could potentially hamper effective conservation efforts for multiple taxa. We also found that there were more studies conducted for single taxa and non-threatened species. Based on the IUCN Red List, $26.7 \%$ of species are categorised as threatened (critically endangered, endangered, vulnerable, and near threatened), $56.7 \%$ as least concern and $15.2 \%$ as data deficient. Thus, even when compared to the proportion of threatened species globally, our systematic review shows that there is a lack of studies on how habitat loss and fragmentation influence threatened species. The increase in the number of single-species studies suggests that there is growing interest in obtaining a more detailed, mechanistic understanding of habitat fragmentation.

\section{Better understanding habitat loss and fragmentation}

Rapid progress has been made in fragmentation research in the past two decades. Our study shows that pattern-based research is still dominating the fragmentation literature, despite calls for change (Fischer and Lindenmayer 2006; Didham et al. 2012). This can be seen from the choice of response variable, conceptual model and landscape metrics used for conducting the research that are still based more commonly on pattern than ecological processes.

A moderate increase in process-based research reflects changes in the way we perceive and manage landscapes. For example, a shift towards appreciating landscapes as gradients or continuums has led to a renewed focus on the role of 'matrix' habitat in agricultural landscapes (Driscoll et al. 2013). In turn, this has influenced government investment and on-ground management by placing a greater emphasis on landscape wide and off-reserve (or private land) conservation strategies that aim to increase habitat quality and improve connectivity to reduce negative fragmentation effects (Chan and Daily 2008; Arponen et al. 2013; Duarte et al. 2014).

Different conceptual models, study designs and landscape measures have different strengths and limitations (Table A10), and the approach used for a given study will depend on the study objectives and the ecological and landscape management contexts. Although understanding pattern is important in ecological research, understanding the mechanisms and underlying processes of how species respond to landscape changes is crucial if we are to understand relationships between biodiversity and ecosystems, a necessary precursor to developing effective management strategies in fragmented landscapes. As both single-species and ecosystem studies have their own strengths and limitations, we recommend a combination of both approaches in order to develop effective management strategies 
and increase the potential for successful conservation outcomes in fragmented landscapes (see also Lindenmayer et al. (2007).

The geographical and taxonomic biases that we found in the literature limit our understanding of biodiversity and ecosystem function in different fragmented landscapes. Knowledge gaps caused by these biases could further limit the development and the implementation of effective strategies for managing habitat loss and fragmentation in areas where the crisis is greatest. The increasing number of studies conducted in tropical developing countries means that the focus of attention is currently shifting to where conservation is needed the most. We suggest that more attention be given to further promote and facilitate research in these understudied regions to improve empirical evidence of biodiversity persistence and appropriate habitat management in these landscapes.

\section{Acknowledgments}

We thank several reviewers for useful comments that improved the manuscript. Fardila received an international Australia Awards Postgraduate Scholarship funded by the Australian Government.

\section{Literature Cited}

Arponen A, Heikkinen RK, Paloniemi R, Pöyry J, Similä J, Kuussaari M., 2013. Improving conservation planning for semi-natural grasslands: Integrating connectivity into agri-environment schemes. Biol. Conserv. 160:234-241.

Baguette M., 2004. The classical metapopulation theory and the real, natural world: A critical appraisal. Basic Appl. Ecol. 5:213-224.

Bennett AF, Radford JQ, Haslem A, 2006. Properties of land mosaics: Implications for nature conservation in agricultural environments. Biol. Conserv. 133:250264.

Bocedi G, Zurell D, Reineking B, Travis JM., 2014. Mechanistic modelling of animal dispersal offers new insights into range expansion dynamics across fragmented landscapes. Ecography 37:1240-1253.

Brennan JM, Bender DJ, Contreras TA, Fahrig L., 2002. Focal patch landscape studies for wildlife management: Optimizing sampling effort across scales. In: Liu J, Taylor WW (eds). Integrating Landscape Ecology into Natural Resource Management. Cambridge University Press, Cambridge, pp 68-91.

Bridge ES, Thorup K, Bowlin MS, Chilson PB, Diehl RH, Fléron RW, Hartl P, Kays R, Kelly JF, Robinson WD., 2011. Technology on the move: Recent and forthcoming innovations for tracking migratory birds. BioScience 61:689-698.

Bruton MJ, Maron M, Levin N, McAlpine CA., 2015. Testing the relevance of binary, mosaic and continuous landscape conceptualisations to reptiles in regenerating dryland landscapes. Landsc. Ecol. 30:715-728.

Burgman M, Jarrad F, Main E., 2015. Decreasing geographic bias in conservation biology. Conserv. Biol. 29:1255-1256.

Calabrese JM, Fagan WF., 2004. A comparison-shopper's guide to connectivity metrics. Front. Ecol. Environ. 2:529-536. 
Chan KM, Daily GC., 2008. The payoff of conservation investments in tropical countryside. Proc. Natl. Acad. Sci. U.S.A. 105:19342-19347.

Colwell RK., 2009. Biodiversity: Concepts, patterns, and measurement. In: Levin SA, Carpenter SR, Godfray HCJ, Kinzig AP, Loreau M, Losos JB, Walker B, Wilcove DS (eds). The Princeton Guide to Ecology. Princeton University Press, Princeton, New Jersey, pp 257-263

Cronin DT, Owens JR, Choi H, Hromada S, Malhotra R, Roser F, Bergl R., 2014. Where has all our research gone? A 20-year assessment of the peer-reviewed wildlife conservation literature. Int. J. Comp. Psychol. 27:101-116.

Cushman SA, Gutzweiler K, Evans JS, McGarigal K., 2010. The gradient paradigm: A conceptual and analytical framework for landscape ecology. In: Cushman SA, Huettmann F (eds). Spatial Complexity, Informatics, and Wildlife Conservation. Springer, Tokyo, pp 83-108

Dauber J, Bengtsson J, Lenoir L., 2006. Evaluating effects of habitat loss and land-use continuity on ant species richness in seminatural grassland remnants. Conserv. Biol. 20:1150-1160.

Debinski DM, Holt RD., 2000. A survey and overview of habitat fragmentation experiments. Conserv. Biol. 14:342-355.

Deikumah JP, McAlpine CA, Maron M., 2014. Biogeographical and taxonomic biases in tropical forest fragmentation research. Conserv. Biol. 28: 1522-1531.

Diamond M., 1975 The island dilemma: lessons of modern biogeographic studies for the design of natural reserves. Biol. Conserv. 7: 129-146.

Didham RK, Kapos V, Ewers RM., 2012. Rethinking the conceptual foundations of habitat fragmentation research. Oikos 121:161-170.

Driscoll DA, Banks SC, Barton PS, Ikin K, Lentini P, Lindenmayer DB, Smith AL, Berry LE, Burns EL, Edworthy A., 2014. The trajectory of dispersal research in conservation biology. Systematic review. Plos One 9:e95053.

Driscoll DA, Banks SC, Barton PS, Lindenmayer DB, Smith AL., 2013. Conceptual domain of the matrix in fragmented landscapes. Trends Ecol. Evol. 28:605-613.

Duarte J, Farfán MA, Fa JE, Vargas JM., 2014. Soil conservation techniques in vineyards increase passerine diversity and crop use by insectivorous birds. Bird Study 61:193-203.

Dunn AG, Majer JD., 2007. In response to the continuum model for fauna research: A hierarchical, patch - based model of spatial landscape patterns. Oikos 116:1413-1418.

Duputie A, Zimmermann NE, Chuine I., 2014. Where are the wild things? Why we need better data on species distribution. Glob. Ecol. Biogeogr. 23:457-467.

Ewers RM, Didham RK., 2006. Confounding factors in the detection of species responses to habitat fragmentation. Biol. Rev. 81:117-142.

Ewers RM, Didham RK, Fahrig L, Ferraz G, Hector A, Holt RD, Kapos V, Reynolds G, Sinun W, Snaddon JL., 2011. A large-scale forest fragmentation experiment: The stability of altered forest ecosystems project. Philos. Trans. R. Soc. B. 366:3292-3302. 
Ewers RM, Marsh CJ, Wearn OR., 2010. Making statistics biologically relevant in fragmented landscapes. Trends Ecol. Evol. 25:699-704.

Fahrig L., 2003. Effects of habitat fragmentation on biodiversity. Annu. Rev. Ecol. Evol. Syst. 34:487-515.

Fahrig L., 2015. Just a hypothesis: A reply to Hanski. J. Biogeogr. 42:993-994.

Fahrig L, Baudry J, Brotons L, Burel FG, Crist TO, Fuller RJ, Sirami C, Siriwardena GM, Martin JL., 2011. Functional landscape heterogeneity and animal biodiversity in agricultural landscapes. Ecol. Lett. 14:101-112.

Fischer J, Lindenmayer DB., 2006. Beyond fragmentation: The continuum model for fauna research and conservation in human-modified landscapes. Oikos 112:473-480.

Fischer J, Lindenmayer DB., 2007. Landscape modification and habitat fragmentation: A synthesis. Glob. Ecol. Biogeogr. 16:265-280.

Forman RT, Godron M., 1981. Patches and structural components for a landscape ecology. BioScience 31:733-740.

Gardner TA, Barlow J, Chazdon R, Ewers RM, Harvey CA, Peres CA, Sodhi NS., 2009. Prospects for tropical forest biodiversity in a human-modified world. Ecol. Lett. 12:561-582.

Griffiths RA, Dos Santos M., 2012. Trends in conservation biology: Progress or procrastination in a new millennium? Biol. Conserv. 153:153-158.

Haddad NM, Brudvig LA, Clobert J, Davies KF, Gonzalez A, Holt RD, Lovejoy TE, Sexton JO, Austin MP, Collins CD., 2015. Habitat fragmentation and its lasting impact on earth's ecosystems. Science Advances 1:e1500052.

Haddaway NR, Pullin AS., 2014. The policy role of systematic reviews: Past, present and future. Springer Sci. Rev. 2:179-183.

Haila Y., 2002. A conceptual genealogy of fragmentation research: From island biogeography to landscape ecology. Ecol. Appl. 12:321-334.

Hanski I., 1994. A practical model of metapopulation dynamics. J. Anim. Ecol. 63:151-162.

Hanski I., 2015. Habitat fragmentation and species richness. J. Biogeogr. 42:989-993.

Hanski I, Gilpin M., 1991. Metapopulation dynamics - brief-history and conceptual domain. Biol. J. Linnean Soc. 42:3-16.

Hargis CD, Bissonette JA, David JL., 1998. The behavior of landscape metrics commonly used in the study of habitat fragmentation. Landsc. Ecol. 13:167186.

Haslem A, Bennett AF., 2008. Birds in agricultural mosaics: The influence of landscape pattern and countryside heterogeneity. Ecol. Appl. 18:185-196.

Hilbe JM., 2009. Logistic regression models. CRC Press, Boca Raton, Florida

Holmgren M, Schnitzer SA., 2004. Science on the rise in developing countries. PLoS Biol. 2:e1.

Kool JT, Moilanen A, Treml EA., 2013. Population connectivity: Recent advances and new perspectives. Landsc. Ecol. 28:165-185. 
661

662

663

664

665

666

667

668

669

670

671

672

673

674

675

676

677

678

679

680

681

682

683

684

685

686

687

688

689

690

691

692

693

694

695

696

697

698

699

700

701

702

Laurance WF, et al., 2011a. The fate of Amazonian forest fragments: A 32-year investigation. Biol. Conserv. 144:56-67.

Laurance WF, et al., 2011b. The 10 Australian ecosystems most vulnerable to tipping points. Biol. Conserv. 144:1472-1480.

Laurance WF, et al., 2012. Averting biodiversity collapse in tropical forest protected areas. Nature 489:290-294.

Lindenmayer DB, Fischer J., 2007. Tackling the habitat fragmentation panchreston. Trends Ecol. Evol. 22:127-132.

Lindenmayer DB, et al. ., 2007. The complementarity of single-species and ecosystem-oriented research in conservation research. Oikos 116:1220-1226.

Lindenmayer DB, Franklin JF, Fischer J., 2006. General management principles and a checklist of strategies to guide forest biodiversity conservation. Biol. Conserv. 131:433-445.

MacArthur R, Wilson E., 1967. The Theory of Island Biogeography. Princeton University Press, Princeton, New Jersey.

Mallett R, Hagen-Zanker J, Slater R, Duvendack M., 2012. The benefits and challenges of using systematic reviews in international development research. J. Dev. Effect. 4:445-455.

Manning AD, Lindenmayer DB, Nix HA., 2004. Continua and umwelt: Novel perspectives on viewing landscapes. Oikos. 104:621-628.

Mantyka-Pringle CS, Martin TG, Rhodes JR., 2012. Interactions between climate and habitat loss effects on biodiversity: A systematic review and meta-analysis. Glob. Change Biol. 18:1239-1252.

McGarigal K, Cushman SA., 2002. Comparative evaluation of experimental approaches to the study of habitat fragmentation effects. Ecol. Appl. 12:335345.

McGarigal K, Cushman S., 2005. The gradient concept of landscape structure. In: Weins J, Moss M (eds). Issues and Perspectives in Landscape Ecology. Cambridge University Press, Cambridge, pp 112-119.

McGarigal K, Cushman SA, Neel MC, Ene E., 2002. Fragstats: Spatial pattern analysis program for categorical maps, University of Massachusetts, Amherst.

McIntyre S, Hobbs R., 1999. A framework for conceptualizing human effects on landscapes and its relevance to management and research models. Conserv. Biol. 13:1282-1292.

Mortelliti A., Amori G., Capizzi D., Cervone C., Fagiani S., Pollini B., \& Boitani L., 2011. Independent effects of habitat loss, habitat fragmentation and structural connectivity on the distribution of two arboreal rodents. J. Appl. Ecol. 48: 153162.

Millennium Ecosystem Assessment., 2005. Ecosystems and human well-being: Synthesis. Island Press, Washington, DC.

Nathan R, Perry G, Cronin JT, Strand AE, Cain ML., 2003. Methods for estimating long-distance dispersal. Oikos 103:261-273. 
Newbold T, Hudson LN, Arnell AP, Contu S, De Palma A, Ferrier S, Hill SL, Hoskins AJ, Lysenko I, Phillips HR., 2016. Has land use pushed terrestrial biodiversity beyond the planetary boundary? A global assessment. Science 353:288-291.

Newbold T, et al., 2015. Global effects of land use on local terrestrial biodiversity. Nature 520:45-50.

Olson DM, Dinerstein E, Wikramanayake ED, Burgess ND, Powell GV, Underwood EC, D'amico JA, Itoua I, Strand HE, Morrison JC., 2001. Terrestrial ecoregions of the world: A new map of life on earth: A new global map of terrestrial ecoregions provides an innovative tool for conserving biodiversity. 51:933-938.

Price B, McAlpine CA, Kutt AS, Phinn SR, Pullar DV, Ludwig JA., 2009. Continuum or discrete patch landscape models for savanna birds? Towards a pluralistic approach. Ecography 32:745-756.

Prugh LR., 2009. An evaluation of patch connectivity measures. Ecol. Appl. 19:13001310.

Pullin AS, Knight TM., 2009. Doing more good than harm-building an evidence-base for conservation and environmental management. Biol. Conserv. 142:931-934.

Radford JQ, Bennett AF., 2007. The relative importance of landscape properties for woodland birds in agricultural environments. J. Appl. Ecol. 44:737-747.

Saura S, Torne J., 2009. Conefor sensinode 2.2: A software package for quantifying the importance of habitat patches for landscape connectivity. Environ. Modell. Softw. 24:135-139.

Shah VB, McRae B., 2008. Circuitscape: A tool for landscape ecology. Pages 62-66. Proceedings of the 7th Python in Science Conference.

Sokal RR, Rohlf FJ., 1995. Biometry: The principles of statistics in biological research. New York, NY: WH Freeman and Co.

Thornton DH, Branch LC, Sunquist ME., 2011. The relative influence of habitat loss and fragmentation: Do tropical mammals meet the temperate paradigm? Ecol. Appl. 21:2324-2333.

Tischendorf L, Fahrig L., 2000. How should we measure landscape connectivity? Landsc. Ecol. 15:633-641.

Trimble MJ, van Aarde RJ., 2012. Geographical and taxonomic biases in research on biodiversity in human-modified landscapes. Ecosphere 3:art119.

Tscharntke T, et al., 2012. Landscape moderation of biodiversity patterns and processes - eight hypotheses. Biol. Rev. 87:661-685.

Turner WR., 2006. Interactions among spatial scales constrain species distributions in fragmented urban landscapes. Ecol. Soc. 11:6.

United Nations DoEaSA, Population Division., 2013. World population prospects: The 2012 revision, key findings and advance tables. Working Paper.

Uuemaa E, Mander Ü, Marja R., 2013. Trends in the use of landscape spatial metrics as landscape indicators: A review. Ecol. Indic. 28:100-106.

Venables WN, Ripley BD., 2002. Modern Applied Statistics with S. Springer, New York. 
Wiegand T, Revilla E, Moloney KA., 2005. Effects of habitat loss and fragmentation on population dynamics. Conserv. Biol. 19:108-121.

Wiens JA., 1995. Habitat fragmentation - island v landscape perspectives on bird conservation. Ibis 137:S97-S104.

Wiens JA., 2007. Foundation Papers in Landscape Ecology. Columbia University Press, New York.

Wilson JB, Peet RK, Dengler J, Pärtel M., 2012. Plant species richness: The world records. J. Veg. Sci. 23:796-802.

Wilson KA, Meijaard E, Drummond S, Grantham HS, Boitani L, Catullo G, Christie L, Dennis R, Dutton I, Falcucci A., 2010. Conserving biodiversity in production landscapes. Ecol. Appl. 20:1721-1732. 


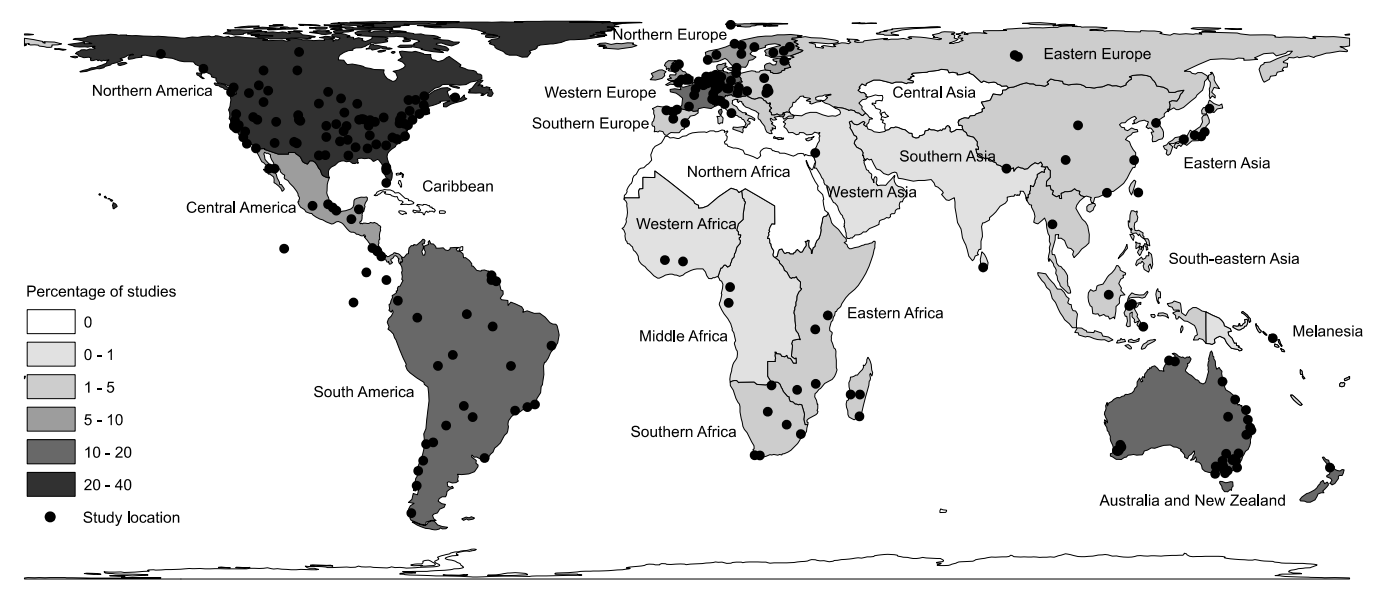

Fig. 1. The location of the 302 habitat loss and fragmentation studies data were extracted from. Shading highlights the percentage of studies by geographic region. 

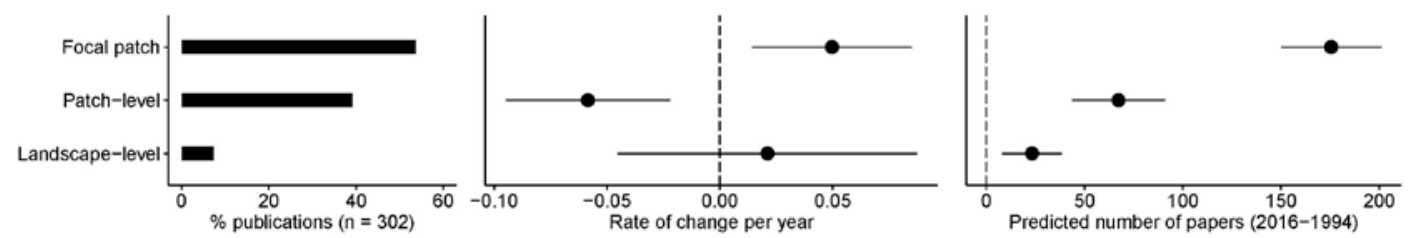

806

807 Fig. 2. Unit of inference. Percentage of sample publications ( $n=302)$, rate of change in 808 proportion of studies per year, and the predicted number of fragmentation papers in 8092016 compared to 1994 for each category of unit of inference. Error bars represented 810 the 95\% confidence interval from a logistic regression.

811

812

813

814

815

816

817

818

819

820

821

822

823

824

825

826

827

828

829

830

831

832

833

834

835

836 

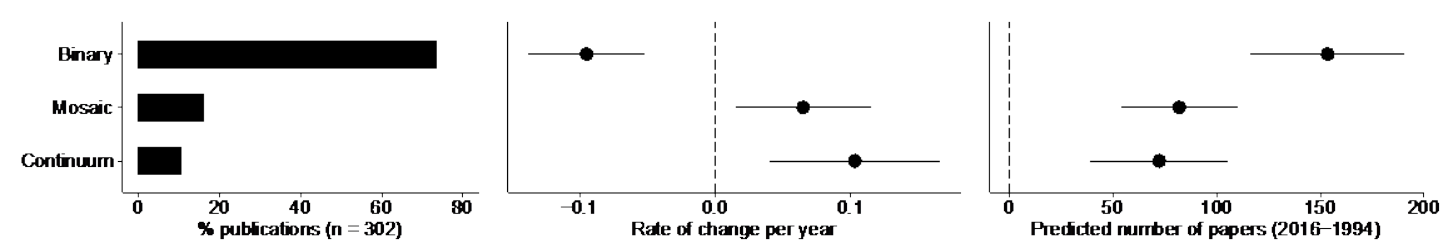

838

839 Fig. 3. Conceptual model. Percentage of sample publications $(n=302)$, rate of change in proportion of studies per year, and the predicted number of fragmentation papers in

841 2016 compared to 1994 for each category of conceptual model. Error bars represented

842 the $95 \%$ confidence interval from a logistic regression.

843

844

845

846

847

848

849

850

851

852

853

854

855

856

857

858

859

860

861

862

863

864

865

866

867

868

869 

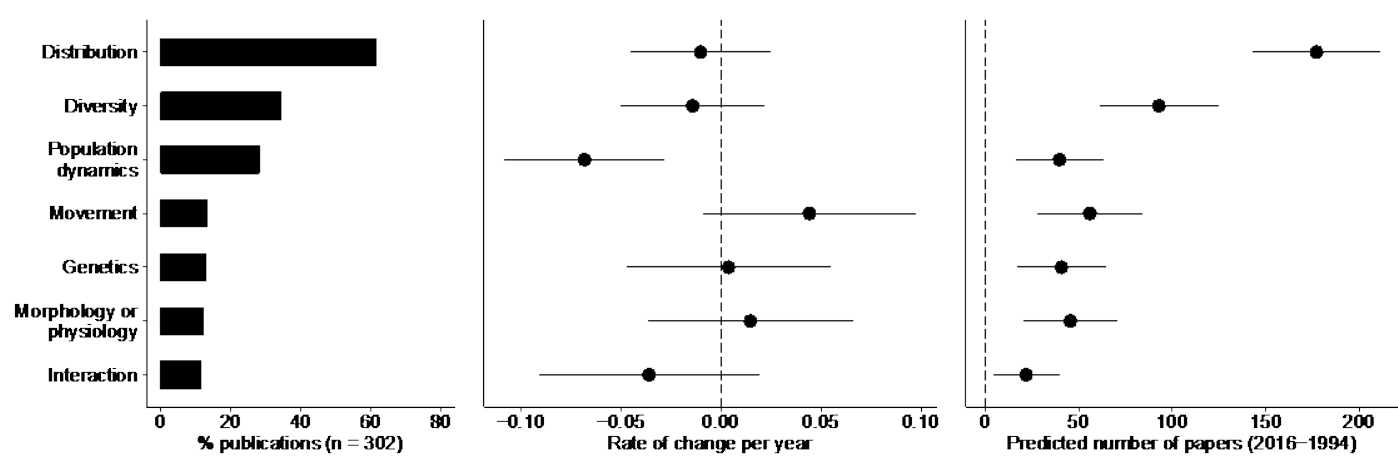

872 Fig. 4. Biodiversity response. Percentage of sample publications (n=302), rate of change in proportion of studies per year, and the predicted number of fragmentation papers in 2016 compared to 1994 for each category of biodiversity response measured

876 

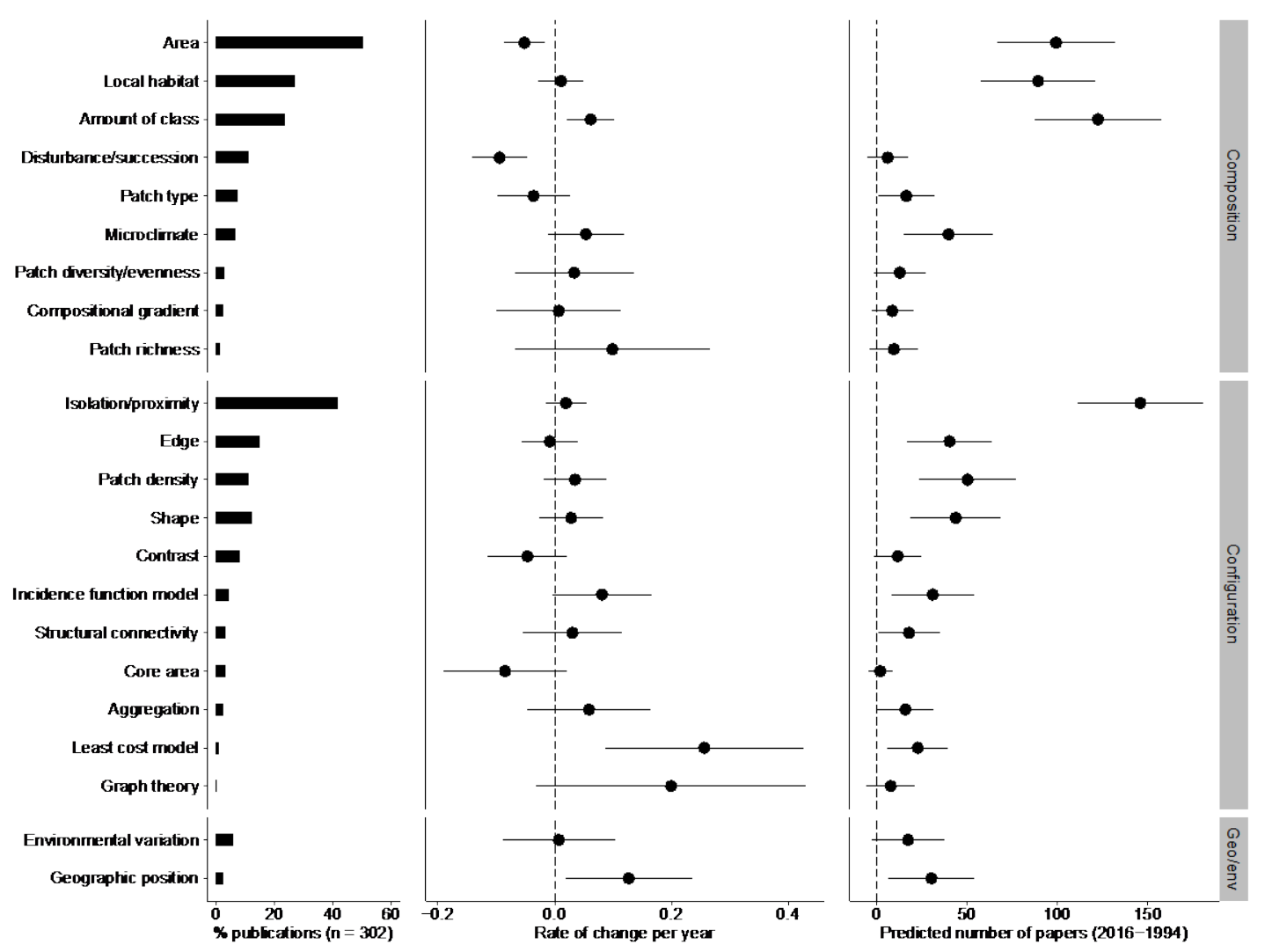

Fig. 5. Landscape metric. Percentage of sample publications $(n=302)$, rate of change in proportion of studies per year, and the predicted number of fragmentation papers in 2016 compared to 1994 for each category of landscape metric used. Error bars represented the $95 \%$ confidence interval from a logistic regression. 


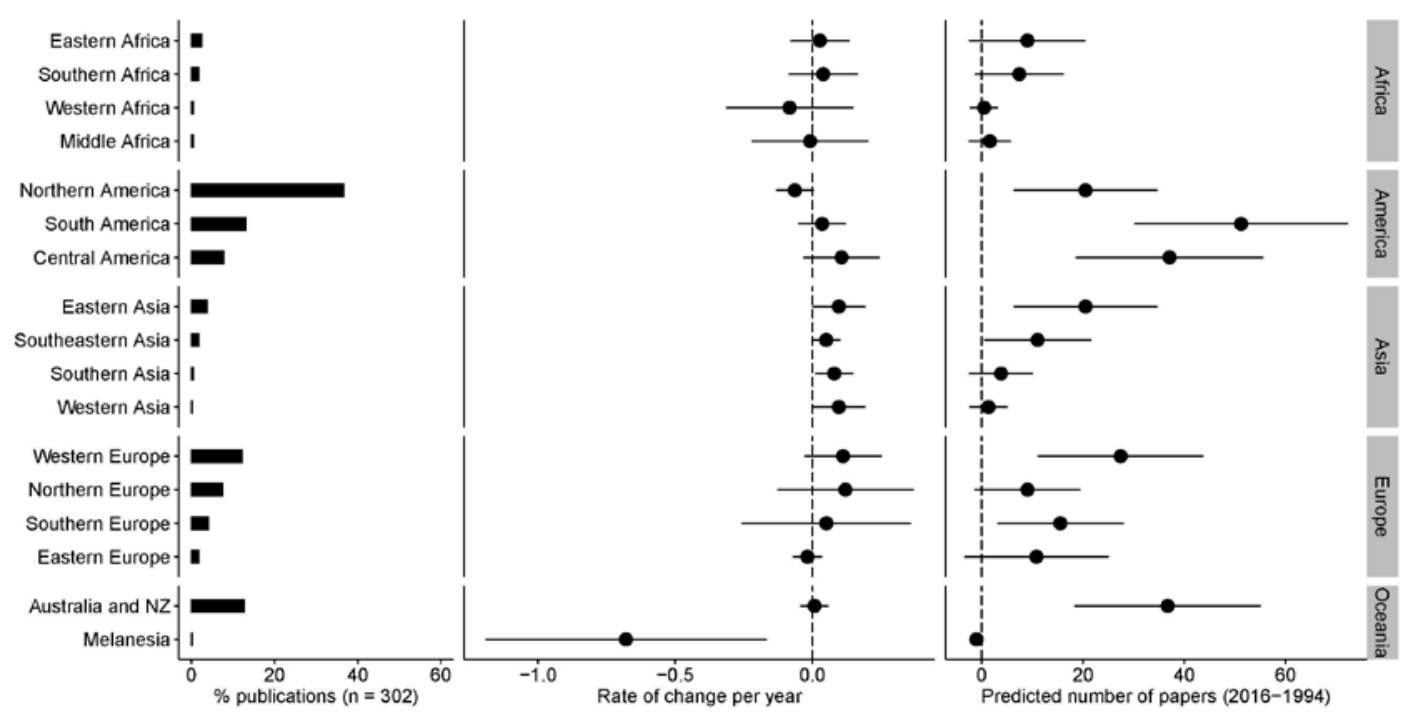

923 Fig. 6. Geographic location. Percentage of sample publications $(n=302)$, rate of change in proportion of studies per year, and the predicted number of fragmentation papers in 2016 compared to 1994 in each geographic location. Error bars represented the $95 \%$ confidence interval from a logistic regression. 

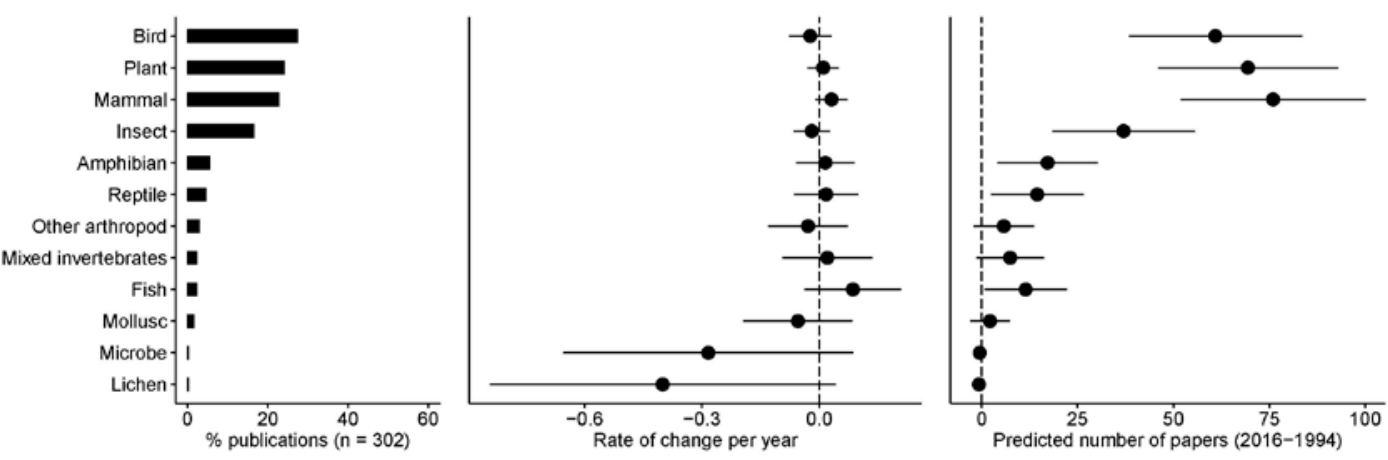

948 Fig. 7. Focal organism. Percentage of all publications (n=302), rate of change in 949 proportion of studies per year, and the predicted number of fragmentation papers in 9502016 compared to 1994 for each category of taxa. Error bars represented the 95\% 951 confidence interval from a logistic regression. 